\title{
Extracting Earthquake Induced Coherent Soil Mass Movements
}

\author{
Kazuo Konagai, Zaheer Abbas Kazmi and Yu Zhao \\ University of Tokyo \\ Japan
}

\section{Introduction}

In the earthquake engineering practice, fragility curves are useful tools for predicting the extent of probable damage. They show the probability of damage to a particular-style structure as a function of strong motion parameters, and they allow estimation of a level of damage probability for a known ground motion index. The problem, however, is that strong ground motion records are often unavailable in seriously devastated areas, thus frustrating all attempts to rationally deduce the whole picture of the devastation at a great cost of many lives and properties. Other than that, we should recognize that not only intense shakes but also ground deformations can be equally or often more responsible for the devastation. Aftermaths of an earthquake are often more devastating than its immediate effect, especially in mountainous terrains. Large strains built up in soils and rocks along a dislocated fault can trigger post-earthquake disasters such as landslides and debris flows, which can last long causing serious problems for rehabilitations and land conservations. Therefore one of what required of us is to deduce as much hidden signs as possible from observable change of landforms.

Earthquake-induced landform changes have a wide range of ground movement. Among them, tectonic deformations under the action of deep-seated forces may hint the presence of a zone of deformed rock along the exposed and/or hidden fault, namely the zones which became more susceptible to landslides than they had been in the past. Coherent mass movements are generally less catastrophic than chaotic mass movements. However, they can surely cause long-lasting problems for rehabilitations. Moreover even a chaotic mass movement can be preceded by a slow and coherent mass movement at its early stage.

Recent development of remote sensing technologies has enabled us to detect precise landform changes in a scientific manner. However, the methods allow us to detect displacements only in the Eulerian description, in which the description of motion is made in terms of the spatial coordinates which does not follow the motion of soil particles. Discussions of earthquake-inflicted geotechnical issues require more direct description of soil particle movements because soils are typically history-dependent materials. The first half of this chapter presents a method to extract Lagrangian components of displacements from available set of elevation data. The method is then applied to an active folding zone affected by the Mid-Niigata Prefecture Earthquake of October 23rd 2004. The surface Lagrangian displacements and the cause-and-effect relationships for the reported damages are discussed in detail. 


\section{Method to extract lagrangian soil displacements}

Nowadays, most common methods to monitor landform changes include GPS control measurement, level measurement, long baseline interface measurement etc. But these measurements are limited to certain areas and only monitor discrete points. Due to the remoteness of disaster struck areas, usually high mountains, and due to its spatial extension, remote sensing is a cost efficient and more practical tool for monitoring terrain dynamics.

Recent development of remote sensing technologies such as Laser Imaging Detection and Ranging Technology (LIDAR), Interferometric Synthetic Aperture Radar (InSAR) and Differential-InSAR has enabled the acquisition of images of landforms and the changes in elevation with high precision. However, the methods allow us to detect displacements only in the Eulerian description. Rather than the Eulerian displacements, we need to extract Lagrangian displacements of soils, whose behaviours are typically history-dependent.

Konagai et al. (2009) proposed a method to estimate Lagrangian components of tectonic displacement considering rigid-body-translation of three consecutive soil patches, their centres arranged in a triangular pattern, with an underlying assumption that tectonic displacement varies gently in space. The method has been improved by the second author incorporating vertical rotation of the soil patch and filtering out landslides and manmade changes.

Assuming that a small patch of ground, having a node $i 1$ mapped upon it, with inclinations of $\theta_{x 1}$ and $\theta_{y 1}$ in $\mathrm{x}$ and $\mathrm{y}$ directions, respectively, moves to a new position, changing the inclinations to $\theta_{x 2}$ and $\theta_{y 2}$ (Figure 1). Describing the method in two dimensional setting, the concept can be made simpler to understand (Figure 2). Referring to Figure 1 and 2, Eulerian change in elevation $\left(\Delta_{z, i 1}\right)$ is expressed in terms of the Lagrangian vector $\left\{\begin{array}{lll}\Delta_{x, k} & \Delta_{y, k} & \Delta_{z, k}\end{array}\right\}$ of the movement of a particular soil particle, $\mathrm{k}$, on this patch as;

$$
\left[\begin{array}{lll}
t_{x 2, i 1} & t_{y 2, i 1} & 1
\end{array}\right]\left\{\begin{array}{c}
\Delta_{x, k} \\
\Delta_{y, k} \\
\Delta_{z, k}
\end{array}\right\}=\Delta_{z, i 1}
$$

Where $t_{x 2, i 1}=-\tan \theta_{x 2}$ and $t_{y 2, i 1}=-\tan \theta_{y 2}$, i.e. direction tangents of the soil patch in its new position.

Arranging three soil patches, $i 1, i 2$ and $i 3$, immediately next to each other in a triangular fashion (Figure 3), and using the displacement of its center $\left\{\begin{array}{lll}\Delta_{x, k} & \Delta_{y, k} & \Delta_{z, k}\end{array}\right\}^{T}$ as the representative Lagrangian displacement vector of the triangle, the following set of solvable simultaneous equations is obtained.

$$
\left\{\begin{array}{l}
\Delta_{z, i 1} \\
\Delta_{z, i 2} \\
\Delta_{z, i 3}
\end{array}\right\}=\left[\begin{array}{lll}
t_{x 2, i 1} & t_{y 2, i 1} & 1 \\
t_{x 2, i 2} & t_{y 2, i 2} & 1 \\
t_{x 2, i 3} & t_{y 2, i 3} & 1
\end{array}\right]\left\{\begin{array}{c}
\Delta_{x, k} \\
\Delta_{y, k} \\
\Delta_{z, k}
\end{array}\right\}=\mathrm{T}\left\{\begin{array}{c}
\Delta_{x, k} \\
\Delta_{y, k} \\
\Delta_{z, k}
\end{array}\right\}
$$

Solving the above set of simultaneous equations (2) for all triangles within the target zone, Lagrangian components of displacement vectors $\left\{\begin{array}{llll}\Delta_{x, k} & \Delta_{y, k} & \Delta_{z, k}\end{array}\right\}^{T}$ can be obtained for the entire target zone. 


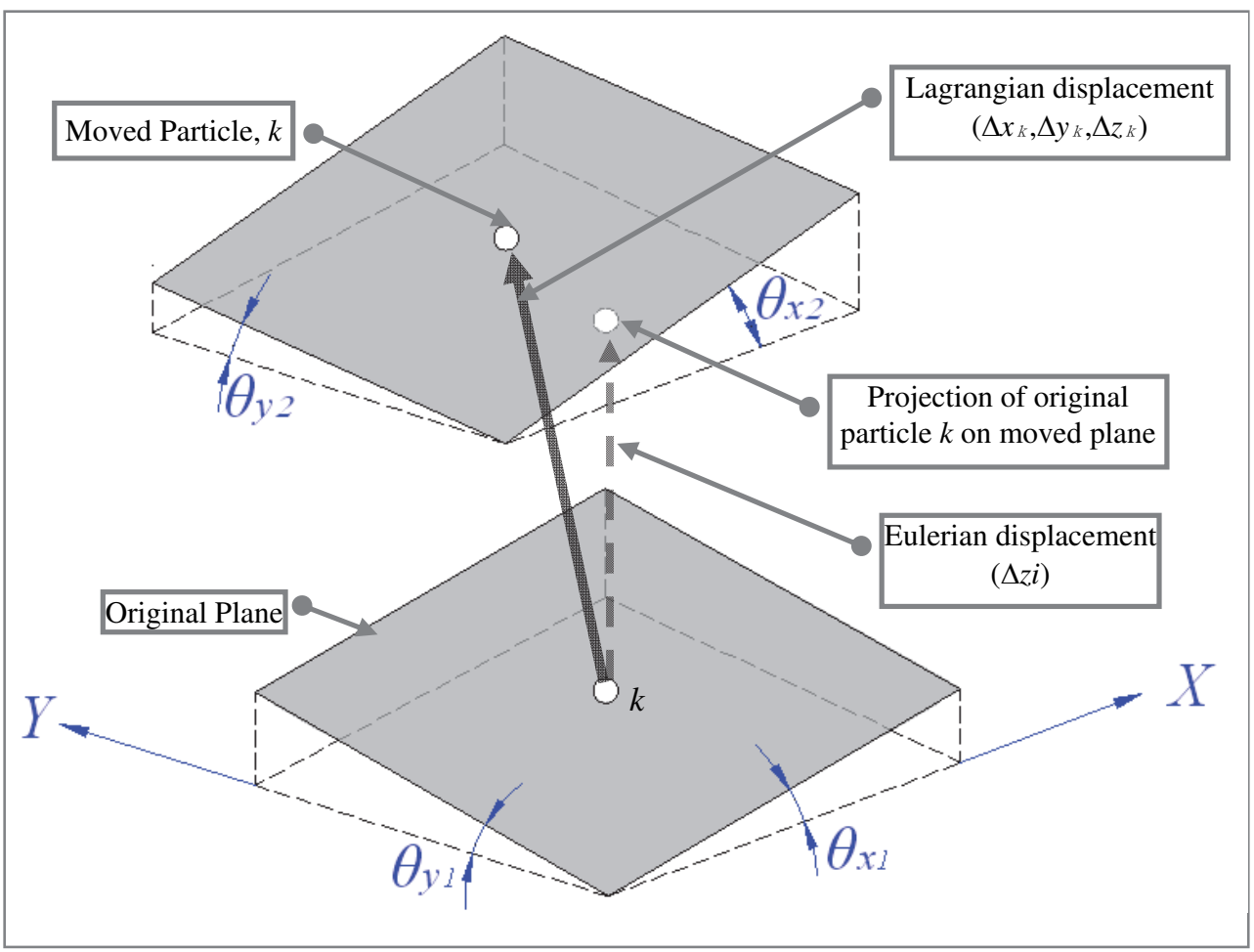

Fig. 1. Description of the method to convert Eulerian change in elevation to Lagrangian displacements
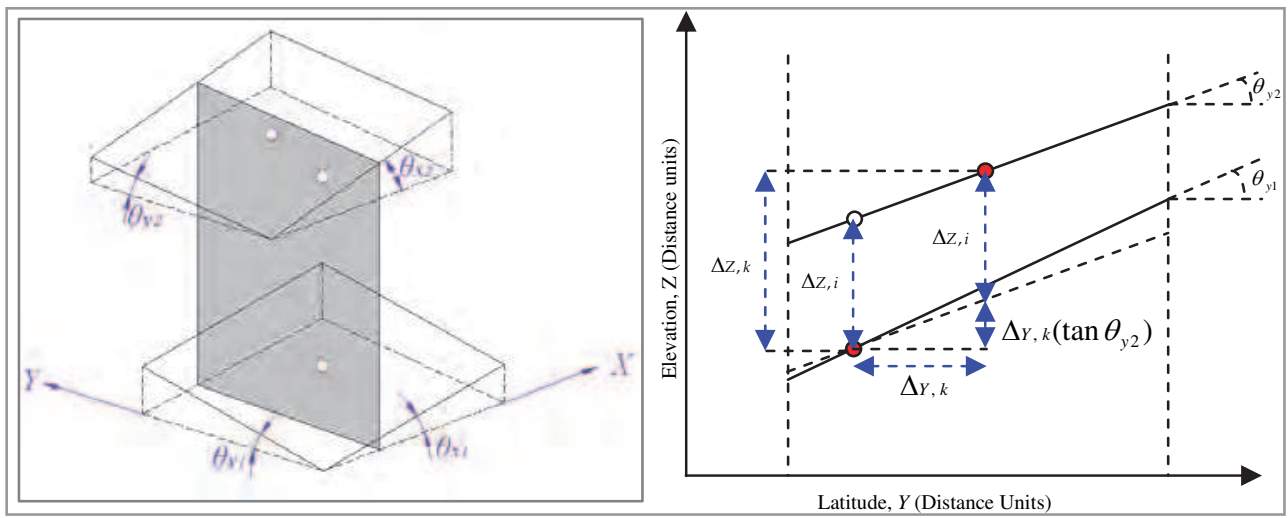

Fig. 2. Description of the method in two dimensional settings to simplify the concept. $\Delta_{z, i}$ is the Eulerian change in elevation while $\left\{\Delta_{\mathrm{x}, \mathrm{k}} \Delta_{\mathrm{y}, \mathrm{k}} \Delta_{\mathrm{z}, \mathrm{k}}\right\}$ are the Lagrangian displacement components. 


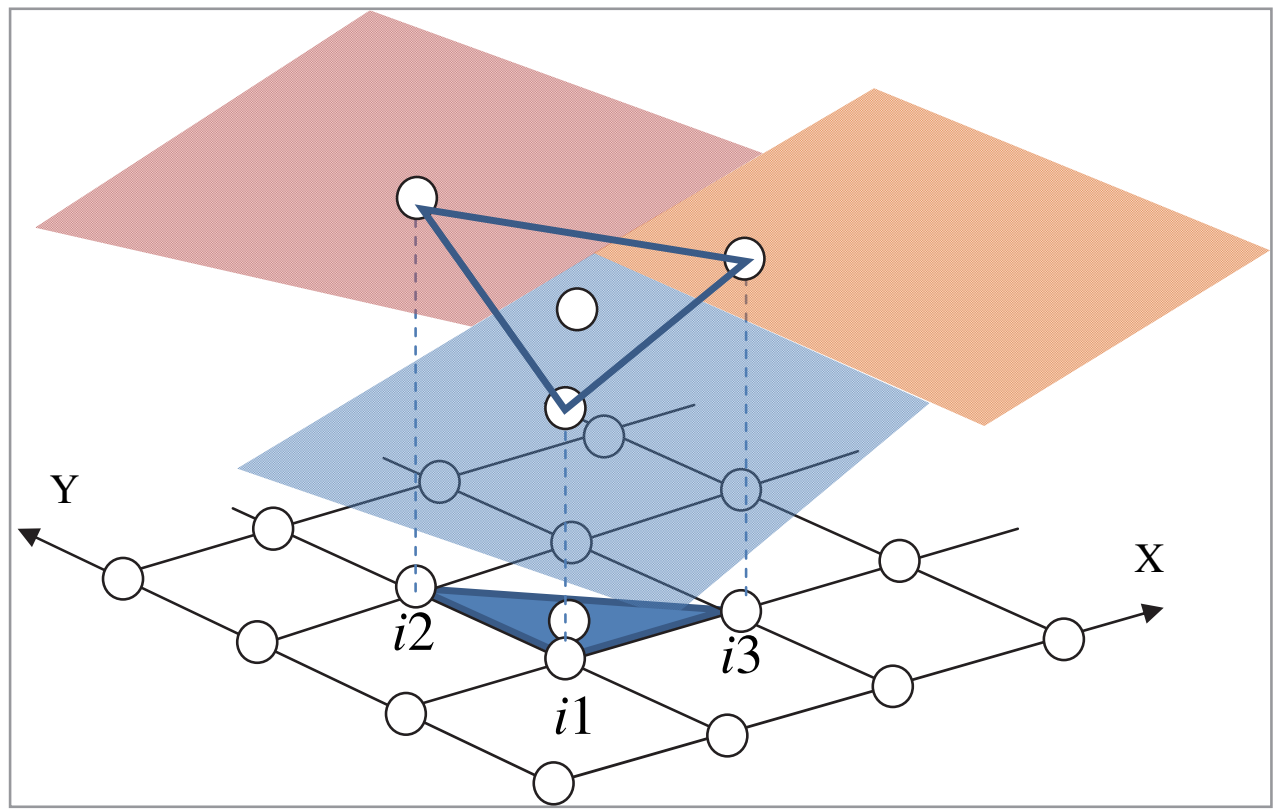

Fig. 3. Three consecutive soil patches arranged in a triangular pattern to solve a set of simultaneous equations for Lagrangian components of displacement.

The obtained Lagrangian vectors show soil particle motions on the ground surface, which can be greatly affected by landslides and manmade changes. To separate tectonic deformations from the entire Lagrangian displacements, landslides and large scale manmade changes are filtered out by limiting the Lagrangian elevation change below a threshold value. This threshold value is set such that the centre of moved plane remains within the projected boundary of the original plan. The following filtering criterion is used;

$\Delta_{z, k}>$ Threshold for Lagrangian vertical displacement

$$
=\left\{\begin{array}{lll}
t_{x 2, i} & t_{y 2, i} & 1
\end{array}\right\}\left\{\begin{array}{lll}
\Delta_{x_{\lim }} & \Delta_{y_{\lim }} & \Delta_{z_{\lim }}
\end{array}\right\}^{T}
$$

Where, $\Delta_{x_{\text {lim }}}$ and $\Delta_{y_{\text {lim }}}$ are half the planner dimensions of the soil patch in $\mathrm{X}$ and $\mathrm{Y}$ direction, respectively. $\Delta_{z_{\text {lim }}}$ is set to a constant value; e.g. while applying to the Mid-Niigata Prefecture Earthquake, this can be determined as 1.36 meters from the maximum vertical displacement of the main shock in this earthquake (Hikima K. and Koketsu K., 2005).

However, the obtained Lagrangian displacement components often show a remarkable scatter. Manmade changes during the time between two DEM's and presence of some nonsurface objects on digital surface models might be most prominent among the possible causes. Therefore, the moving average method was used for overall features of displacements. Assuming that the scattered values follow the Gaussian distribution within a square window, the most frequent value (mode) is interpreted to be the real vector of the soil displacement for this area. Sweeping the entire zone with this square window, one can obtain the whole picture of the deformation. 
The window size is desirable to be larger than the largest hidden landslide in the target area for the discussion of tectonic deformations to minimize the effect of the hidden coherent landslides. For discussing smaller scale soil movements such as hidden coherent landslides, the window size is to be minimized, and yet to be substantially larger than abovementioned manmade changes.

\subsection{III condition}

To obtain a reliable solution, the condition of coefficient matrix $T$ in equation (2) is important. A system of equations is considered to be well-conditioned if a small change in the coefficient matrix or a small change in the right hand side results in a small change in the solution vector. This small change in the solution vector is namely important digits or tolerance of accuracy. The matrix condition can be determined as;

$$
\operatorname{Cond}(T)=a_{\text {tol }} / \varepsilon_{\text {mach }}
$$

Where machine epsilon, $\varepsilon_{\text {mach }}$, gives an upper bound on the relative error due to rounding in floating point arithmetic.

If MATLAB is used for calculation, the machine epsilon of default data type (double precision) is obtained as $\varepsilon_{\text {mach }}=2.2201 \times 10^{-16}$ with "eps" command. Setting the tolerance of calculation accuracy to any desired level, the condition of matrix $T$ can be obtained by equation (4). All the sets of equations not fulfilling this criterion need to be filtered out to get a reliable solution. For the example case described in the following section, $a_{\text {tol }}$ is set at 0.1 .

\section{Extracting coherent mass movements}

\subsection{Active folding zones as target}

Taking a look at history, it is found that earthquakes in active folding areas have distinctive features and can trigger long lasting geotechnical issues. In an active folding zone, the action of deep-seated forces has been shortening sedimentary rock layers causing folded geomorphic surfaces to appear and develop. Looking at a fold surface in profile (Figure 4) upslope and downslope flanks of the fold join together at anticlines and synclines, respectively. Since the up-folded rocks along anticlines have been expanded and cracked over centuries, anticlines frequently have their crests deeply eroded, with a number of debris deposits rimming the eroded hollows. Large-scale landslides are found even on gentle mountain sides dipping towards synclines because their toes are often deeply eroded by rivers. The active folding regions can be thus one of the most landslide-prone zones.

The May $8^{\text {th }}, 1847$ Zenkoji Earthquake $(M=7.4)$ jolted the active folding mountainous terrain west of Nagano, central Japan. Devastations were serious along the entire $50 \mathrm{~km}$ stretch of the Nagano western basin-edge fault that appeared along the skirts of the active folding mountains (Figure 5). The earthquake caused about 44,000 landslides to occur on the hanging wall side of the fault. In 1884, 37 years after the earthquake, a big crack appeared near the southern summit of the Chausu-yama twin peaks and an $800 \mathrm{~m}$ long soil mass started moving. After the heavy rains of 1930, the entire soil mass began to creep down the slope exhibiting thick, wet and sticky features, and the maximum speed of $93 \mathrm{~m} /$ year was reached in 1932-1934. The slope was finally stabilized in the 1970s with a tremendous amount of drainage works that were started in 1965 (Kato H. and Akabane H., 1986). 


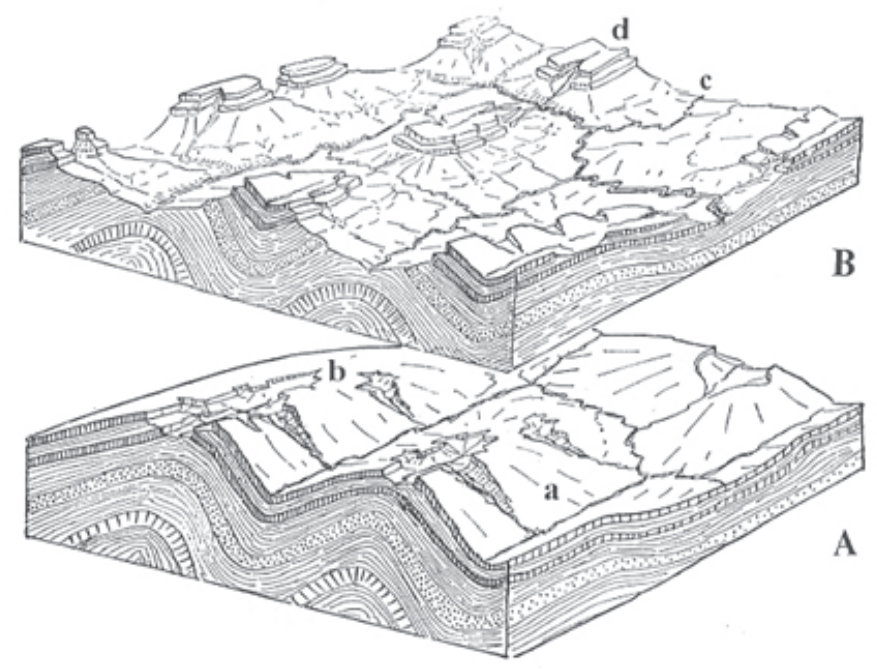

Fig. 4. Erosion of geological fold (Original figure from de Martonne, 1927). Erosion develops from $A$ to $B$ in such a way that syncline valley (a) and anticline ridge (b) in A to become anticline valley (d) and syncline ridge (c) in B, respectively.

A M7.1 earthquake jolted a low-rising mountainous terrain of Senboku, Akita, Japan on March $15^{\text {th }}, 1914$. Though the intensities registered at major cities were not surprisingly large, the reported deaths of 84 among the total 94 were concentrated locally within the $10 \mathrm{~km} \times 10 \mathrm{~km}$ Senboku area. Landslides in Senboku area that appeared in the report of Imperial Earthquake Investigation Committee, No. 82 (1915) and those from the Mid-Niiata Prefecture Earthquake of 2004, which will be explained later, are exactly alike in that just surface laminar sedimentary rocks were detached and slipped down the planar layer boundaries as shown in Figure 6.

The magnitude 6.8 Mid-Niigata Prefecture Earthquake of October 23rd, 2004 jolted one of the areas where active folding geological structure was most clearly recognized (K.H. Yoong and A. Okada, 2005). The hypocenter of the main shock was located at $37.29^{\circ} \mathrm{N}, 138.87^{\circ} \mathrm{E}$ at focal depth of $13 \mathrm{~km}$. The maximum acceleration of $1500 \mathrm{~cm} / \mathrm{s}^{2}$ was recorded at Ojiya K-net station which is about $10 \mathrm{~km}$ west of the epicenter. The main shock was followed by a large number of aftershocks with four being over M6. The focal mechanisms of these strong shocks, estimated by Hi-net and F-net (Honda et al., 2005), were reverse fault type that is concordant with pre-existing fold axis. The epicentres of the aftershocks were distributed along the NNE and SSW direction within a length of about $30 \mathrm{~km}$ (Honda et al., 2005). This earthquake reportedly triggered and/or reactivated thousands of landslides. The economic loss due to these landslides was initially estimated at 8 billion US dollars, making this one of the costliest landslide events in history (Kieffer et al., 2006) and with all similar examples compiled in active folding zones, the quick stabilization of slopes in the Mid-Niigata mountainous terrain was considered to be a pressing need.

In case of Mid-Niigata Prefecture Earthquake, not only landslides but also surface tectonic displacements have caused some problems for rehabilitating the affected areas. As will be discussed hereafter, the tectonic movements have caused the middle part of both the Shinano and Uono rives to be raised upward by about 0.5 to 1.0 meters. Probably due to this 


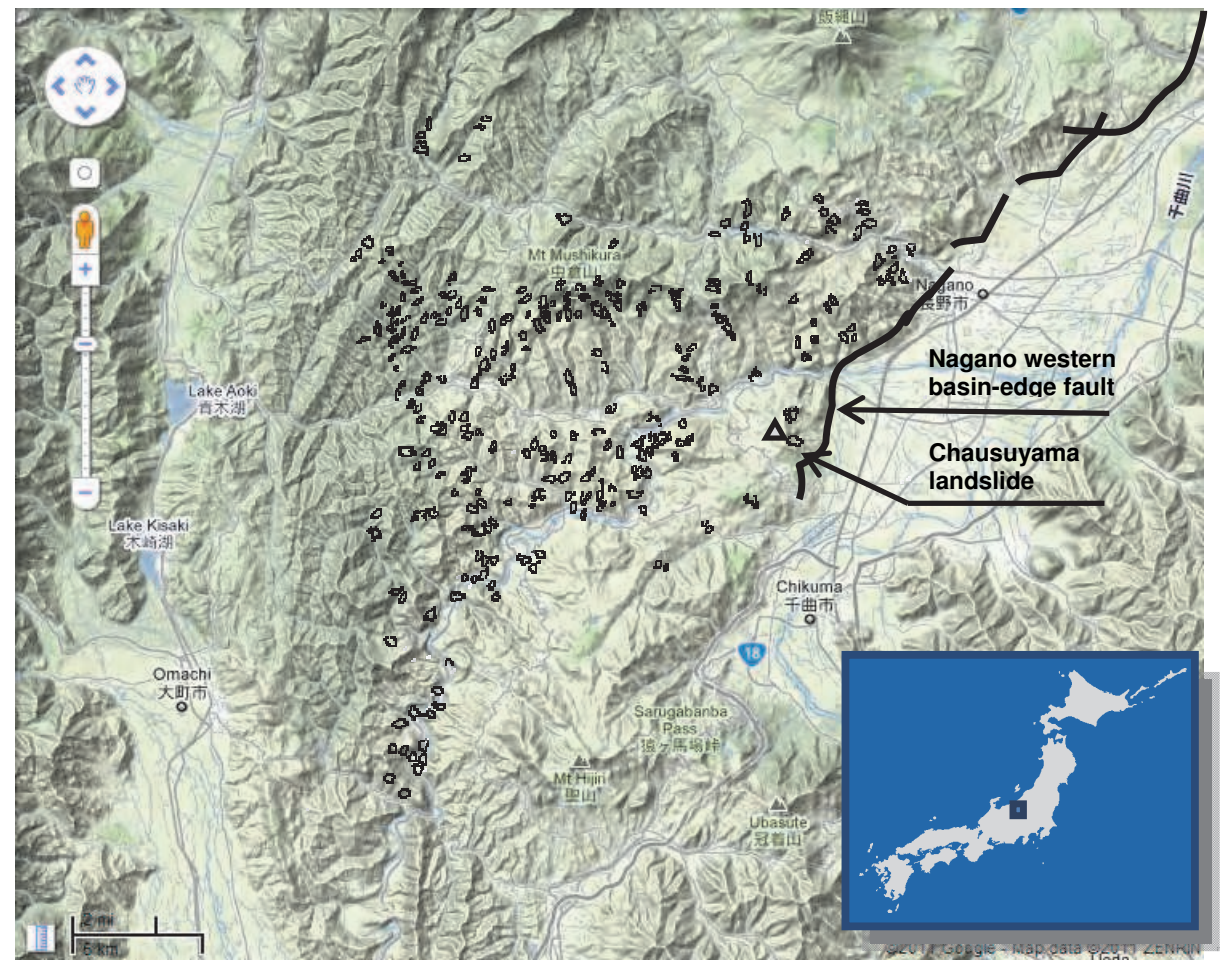

Fig. 5. Landslides caused by the Zenjkoji Earthquake of 1847: The Nagano western basin edge fault is considered to have been responsible for the earthquake. Earthquake-induced landslides distribution is taken from Fig. 1-12 (by Akabane), the Report of Zenkoji Earthquake, Central Disaster Prevention Council (2008). A crack near the southern summit of the Chausu-yama twin peaks (Elevation $730 \mathrm{~m}$, Location: $37.294694^{\circ} \mathrm{N}, 138.875492^{\circ} \mathrm{E}$, triangle mark) began to open wide, which was an early sign of a long-lasting landslide.
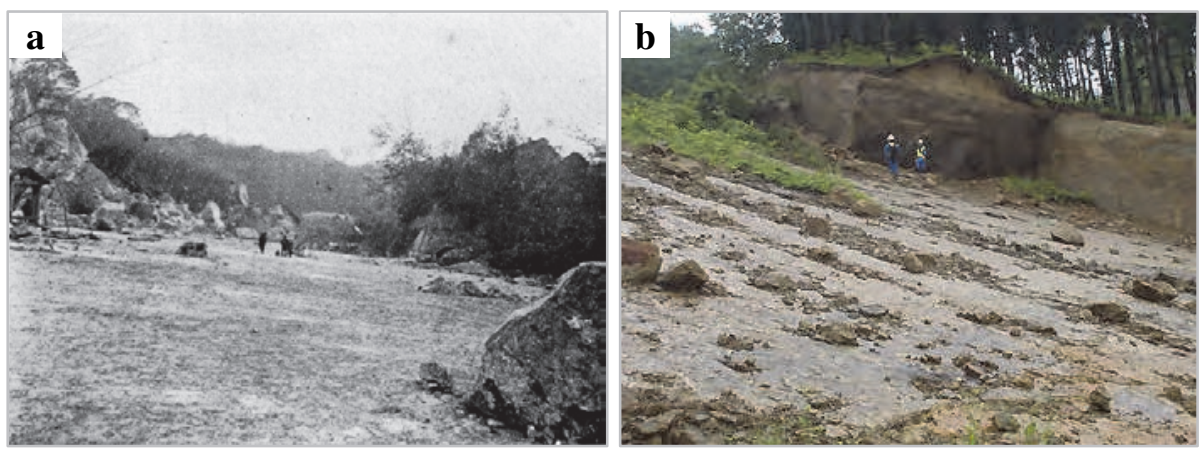

Fig. 6. Similarities between Landslides in the March 15th, 1914 Senboku Earthquake and the October 23rd, 2004 Mid-Niigata Prefecture Earthquake a) Nunomata Landslide in Senboku Earthquake $(39.473419,140.311219)$ b) Uragara landslide in Mid-Niigata Prefecture Earthquake $(39.473419,140.311219)$ 
tectonic deformation, the upper stream reach of the Uono River was flooded in the heavy rain of June, 2005, about eight months after the earthquake. Therefore, the first and essential step for research to proceed and before any rational and scientific discussions on remedial measures to take place, should be to separate soil deformations caused by the tectonic movement of the active folding zone from the overall soil deformations observed on the ground surface. As mentioned above, Interferometric Synthetic Aperture Radar (InSAR) is one of the most advanced technologies to study landform changes (USGS, 2005). However for the Mid-Niigata Prefecture region, thick vegetation and thousands of landslides have made fringe patterns too complicated for extracting pure elevation changes from the available C-band (5.405 GHz) InSAR interferogram from RADSAT, a Canada's commercial SAR satellite (Ozawa et al., 2005). Therefore, digital elevation models (DEMs hereafter) for the mountainous terrain before and after the earthquake were first obtained as raster graphic images with pixels arranged in a $2 \mathrm{~m} \times 2 \mathrm{~m}$ square grid; each pixel has information of its elevation. The DEM for the pre-earthquake time of (1) 1975-1976 was obtained using stereoscopy, and DEMs for the post-earthquake times of (2) Oct. 24, 2004, (3) Oct. 28, 2004, (4) May 2005, (5) May 2006, and (6) May 2007 (JSCE active folding project 2008) were obtained using Laser Imaging Detection and Ranging technology (LIDAR). Changes in elevation in Eulerian description for DEM were first converted to Lagrangian displacements, and then the moving average method was adopted to obtain the whole picture of landform change.

\subsection{Application of the method}

\subsubsection{Surface tectonic displacement}

Target zone is an $11 \times 7 \mathrm{~km}$ active folding area of Yamakoshi mountainous terrain (Figure 7). There were only 13 triangulation points within the target zone and 11 out of those 13 points were not considered to have been affected by landslides. However, the points are so sparsely distributed that a thorough discussion can't be made upon a clear image of displacement. Therefore, precise digital elevation models ( $2 \mathrm{~m}$ resolution) before and one day after the Mid-Niigata Prefecture Earthquake (Oct. 24) were used for the analysis (Figure 8).

The size of the soil patch (Figure 3) is to be determined from the ground features and the objective of the analysis. As is shown in Figure 9, there were a number of manmade changes of landform over the 28 years interval between DEMs prepared in 1976 and 2004. These changes include creation of ponds for Koi-fish farm business, road widening etc. Reflecting these changes, an $8 \mathrm{~m} \times 8 \mathrm{~m}$ soil patch, least square regressed from the points in the square domain surrounding the center point, is used.

First of all large changes in elevation were filtered out by applying the filtering criteria described in section 2. Distribution of the filtered points gives good correlation with the landslide map (Figure 10) (Oyagi et al., 2008). At the lower left corner of the target zone, there is Shinano river and much flatter topography (Figure 8 and 10). Large bunch of filtered points in this area is possibly due to ill conditioned tangential matrices in the flat land.

Figure 11 shows horizontal components of surface tectonic displacement extracted from the DEMs, sweeping the whole target zone with a 1400m smoothening window. Shinano River Office, Hokuriku Regional Bureau of the Ministry of Land, Infrastructure and Transport (MLIT), has been measuring exact locations of bench marks along both the Shinano and Uono rivers on regular basis. Lateral components of the bench marks' displacements due to the earthquake were also plotted on Figure 11. There is a NNE-SSW trending 1 to $2 \mathrm{~km}$ wide belt of large eastward movement to the west of and along the Kajigane syncline. This belt of 


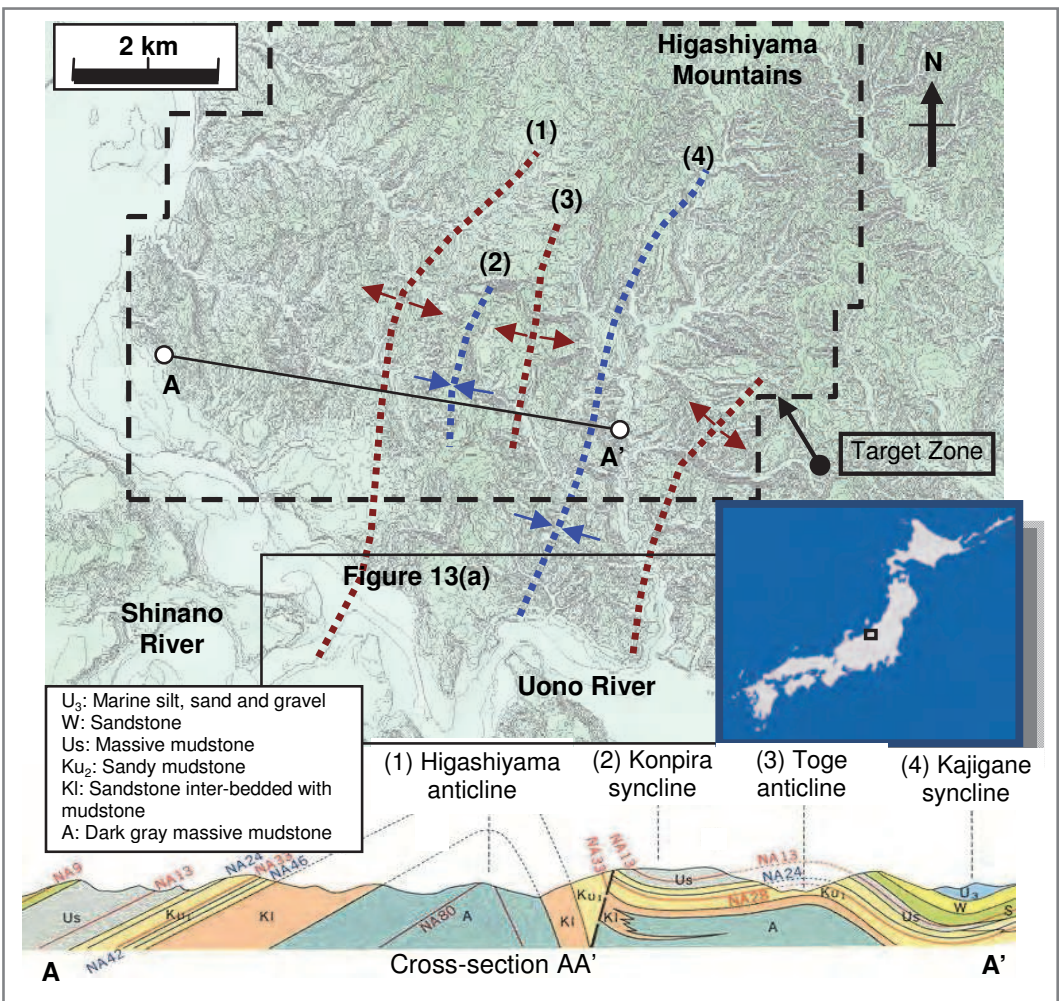

Fig. 7. Target zone on Zone VIII of the Japanese National Grid System
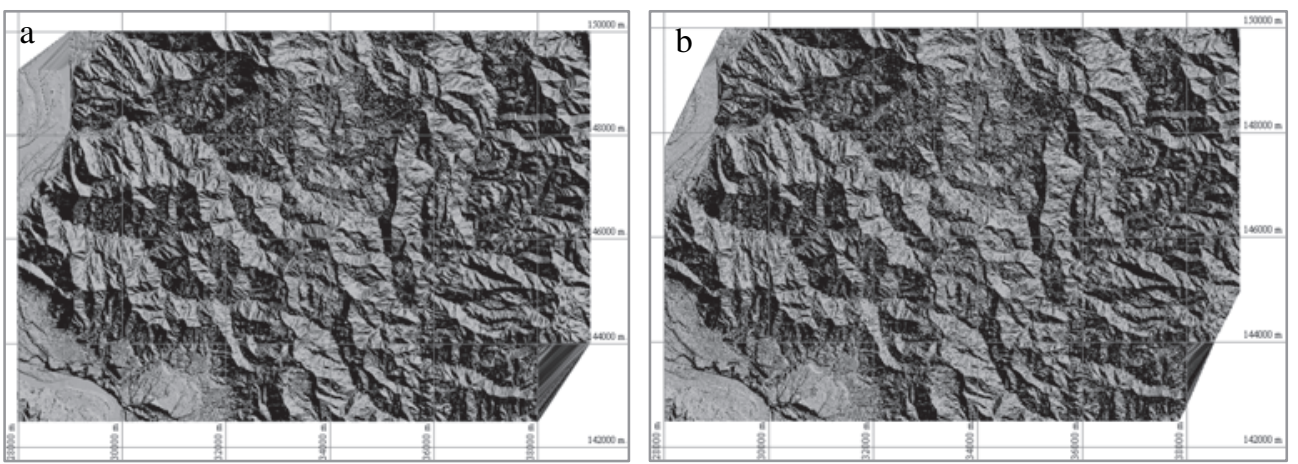

Fig. 8. Topography of target zone prepared from a) 1976 DEM b) 2004 DEM (Zone VIII of the Japanese National Grid System)

lateral displacements seems to have appeared on the hanging wall side of the line of intersection between the ground surface and the straight extension of the hidden deepdipping fault rupture plane for the major event, whose geometry was estimated by Hikima 
and Koketsu (2005). The second cluster of large lateral displacement vectors that has appeared 4 to 5 kilometers west of the Kajigane Syncline, is near the projection on the ground surface of the hidden fault rupture plane for the first largest aftershock of M6.3, which took place at 18:03 JST, about 7 minutes after the main event (Hikima K. and Koketsu K., 2005). While comparing the lateral components of tectonic displacements with landslide map of Figure 10(a), it is found that large clusters of tectonic displacements are concordant with thick clusters of landslides.
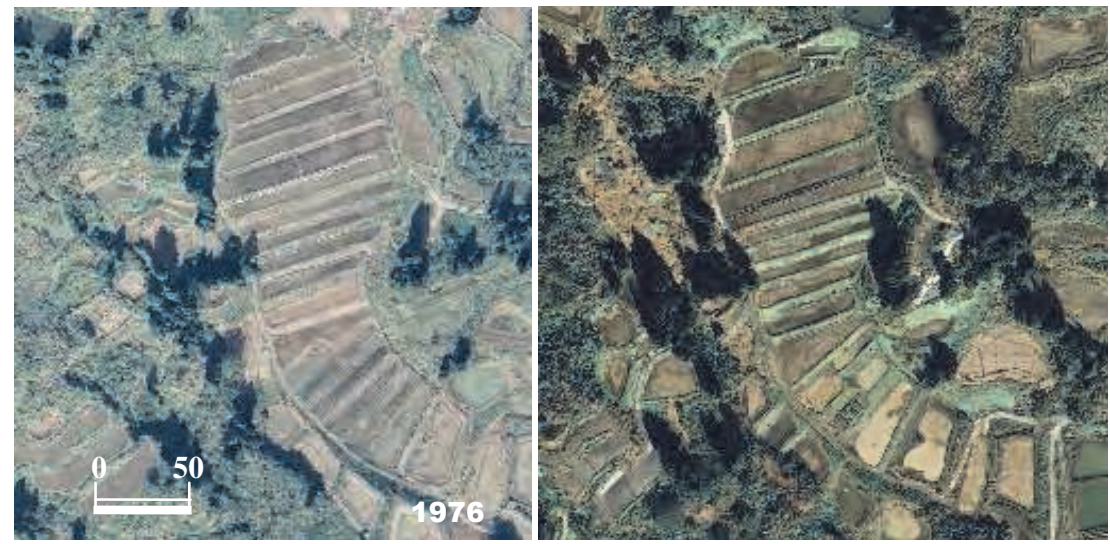

Fig. 9. Improvement of farmland in Yamakoshi: Location of the lower left corner of each photo is $37.337928^{\circ} \mathrm{N}, 138.878678^{\circ} \mathrm{E}$. The left and right photos were taken respectively in 1976 (Geospatial Information Authority of Japan) and on Oct. 24th 2004 (JSCE Active folding Project, 2008). Some of the terraced paddy fields were converted to Koi fish ponds.
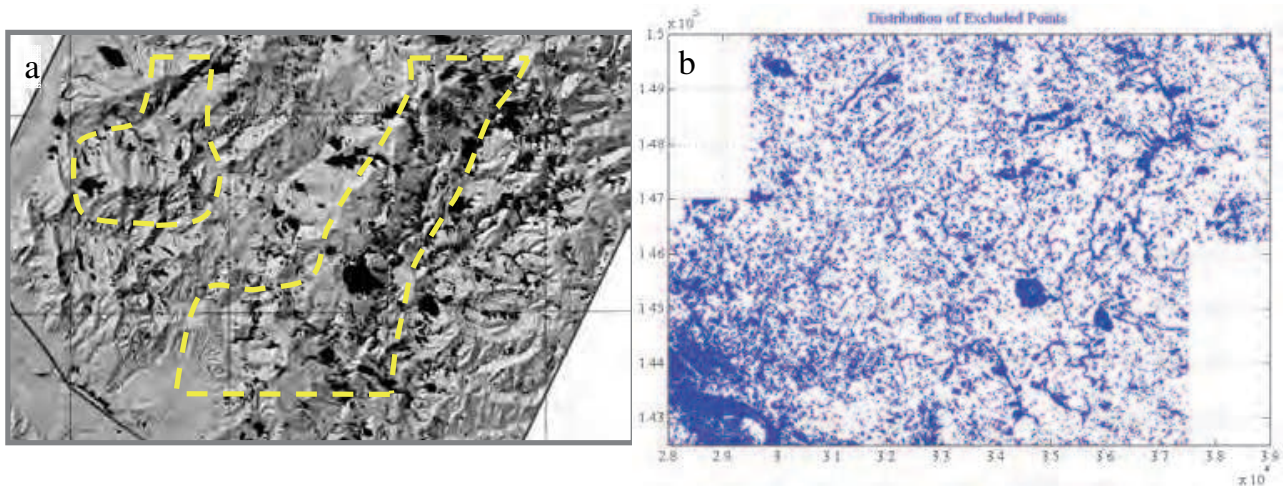

Fig. 10. a) Landslide map of the target zone and b) distribution of the filtered points for landslides and manmade changes (Broken yellow lines show two thick clusters of landslides which will be compared to large lateral displacements shown in Figure 11).

Figure 12 shows vertical components of estimated tectonic displacement. It is notable that there are two areas in the target zone, which have been pushed up by 0.5 to 1.0 meters. The 
most remarkable hump spreads wide across the southwestern part of the target zone where the Uono River joins the Shinano River. The Uono River, after flowing straight west through a flat wide spread valley of Horinouchi, meets the sedimentary silty sand rock ridge (Figure 13(a)). The river then abruptly changes its direction, from SE-NW to NE-SW, along this rock ridge, making a sharp down-folded bend. Then it forces its way through the narrow and lowest points among the mountains making a sharp up-folded bend. On the geological map of this area (Yanagisawa et al., 1986), the approximately $2 \mathrm{~km}$-long stretch of the Uono River between these two bends continues straight to both the Kajigane and the Kodaka synclines at its north and south ends, respectively, suggesting that this $2 \mathrm{~km}$-long stretch of the river is a part of the large Kajigane syncline.

As was explained in 3.1, areas along the upper reach of this part of the Uono River were flooded due to heavy rainfall of June 27th-28th, 2005, about 8 months after the earthquake (Figure 13). Assuming that the same amount of water in the 2005 rain flowed down the Uono River as existed before the earthquake (ignoring the landform changes caused by the Mid-Niigata Prefecture Earthquake), possible water depths at all bench marks along the $57.5 \mathrm{~km}$-long flooded zone (from BM No. 15 at $37.26642^{\circ} \mathrm{N}, 138.862209^{\circ} \mathrm{E}$, to BM No. 72.5 at

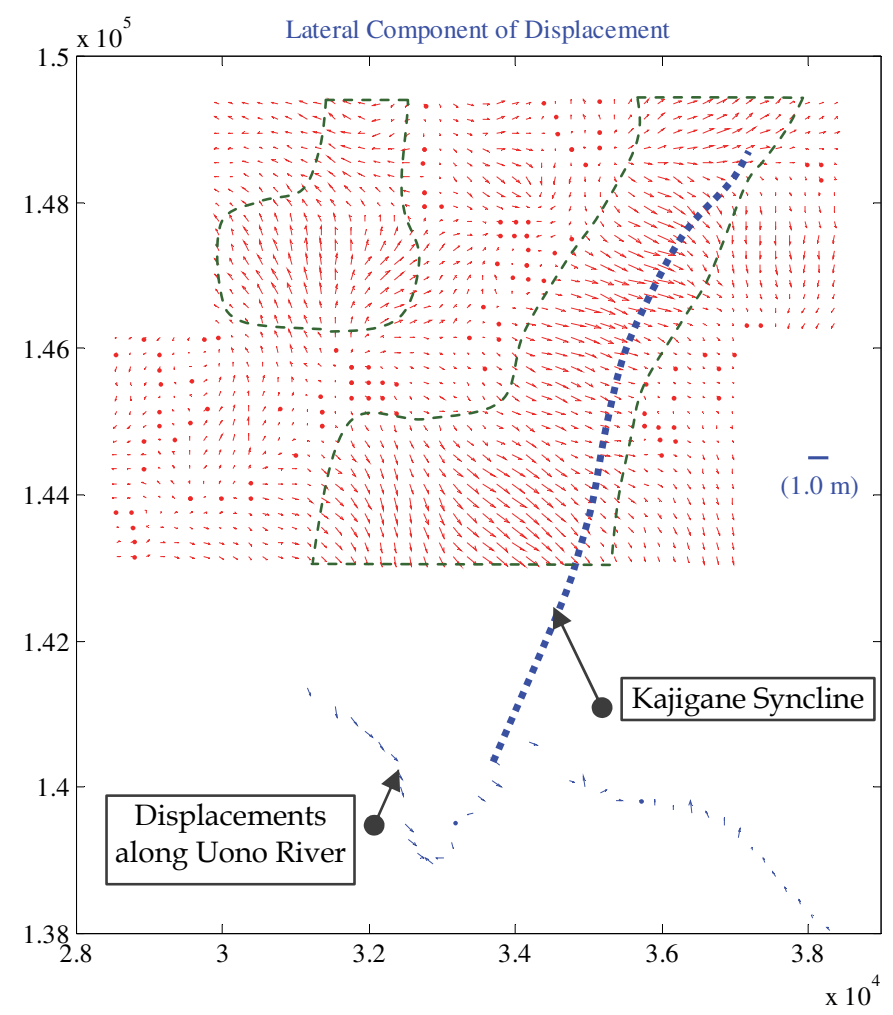

Fig. 11. Lateral components of surface tectonic displacement of the target zone on Zone VIII of the Japanese National Grid System. Broken green lines show two clusters of large lateral displacement which are consistent with thick clusters of landslides shown in Fig. 10(a). 
$37.25923^{\circ} \mathrm{N}, 138.899975^{\circ} \mathrm{E}$ ) were estimated by using the Manning empirical equation (open circles in Figure 14 (Dooge J.C.I., 1992)). For this estimation, precise dimensions for the river cross-sections and inclinations at all benchmarks before and after the earthquake were provided by the Shinano River Office, Hokuriku Regional Bureau of the Ministry of Land, Infrastructure and Transport (MLIT).

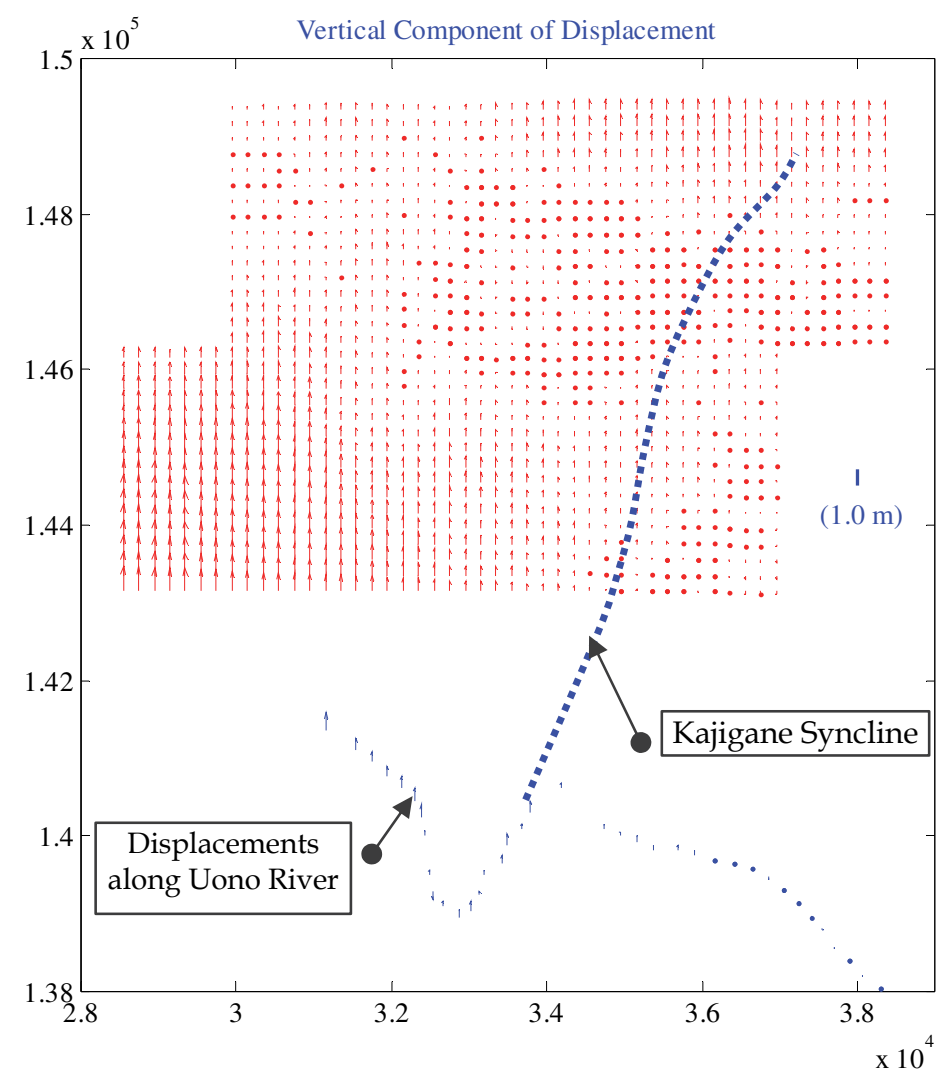

Fig. 12. Vertical components of surface tectonic displacement of the target zone on Zone VIII of the Japanese National Grid System.

Solid circles in Figure 14 show the actual water levels at all bench marks reached in the 2005 flood, while open circles show virtual water levels calculated for the Uono River as it existed before the earthquake. At almost all points, the virtual water levels (open circles) are lower than those (solid circles) reached in the 2005 real flood. Actual water levels were higher than the high water levels (HWL) at bench marks \# 37.5, \# 52.5 and \# 62.5, while virtual water levels at these points do not reach the high water levels. This figure thus suggests that there was a cause-and-effect relation between the earthquake-induced tectonic deformation and the flooding of June, 2005. 

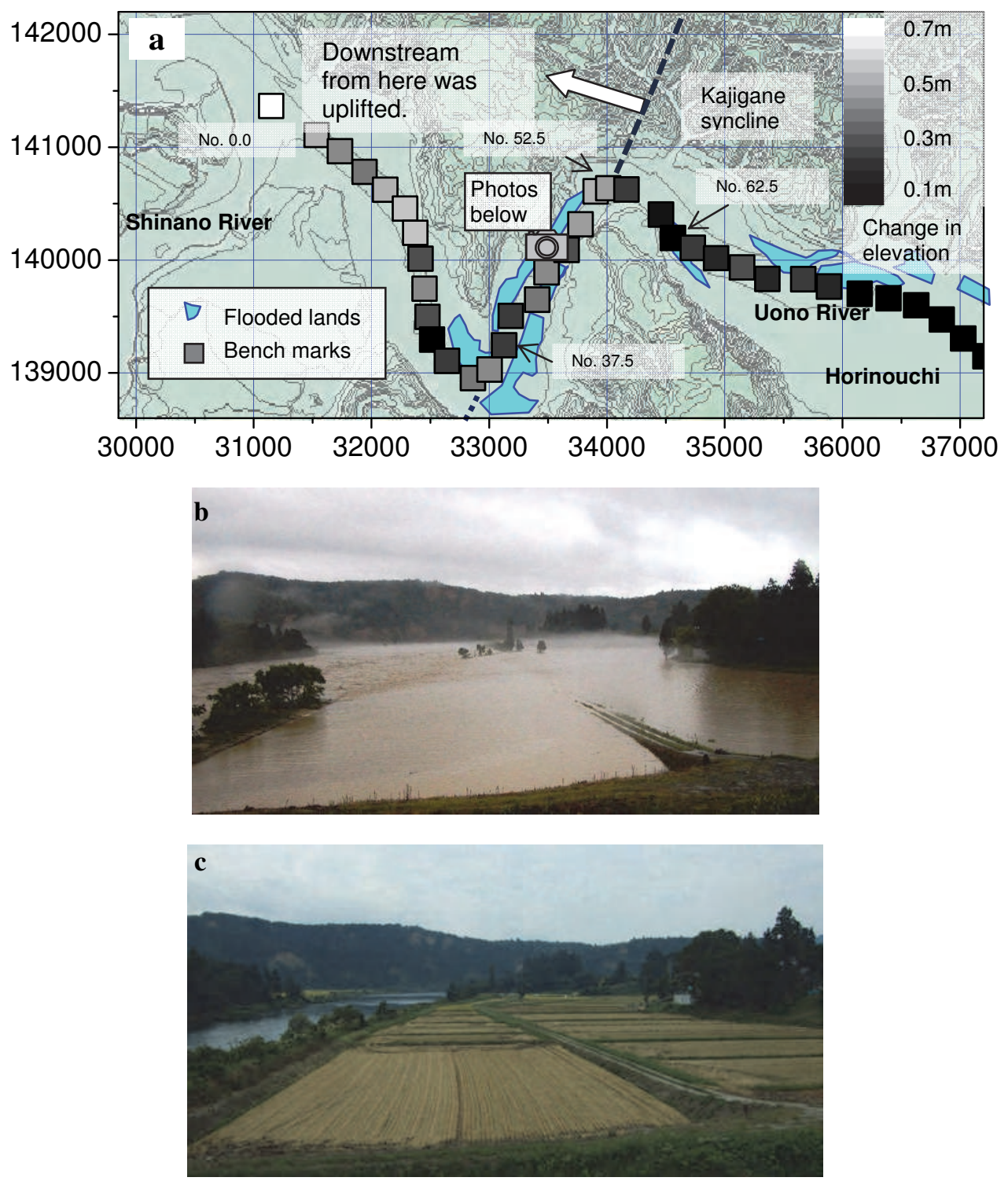

Fig. 13. Farmlands flooded in the heavy rain of June, 2005, about eight months after the earthquake. (a) Locations of flooded farm lands (Hokuriku Regional Agricultural Administration Office, Ministry of Agriculture, Forestry and Fisheries, and Uonuma City), and change in elevations at benchmarks along Uono River on Zone VIII of the Japanese National Grid System (Shinano River Office, Hokuriku Regional Bureau of MLIT) (b) Flooded area near Benchmark No. 42.5km (Photo by Kotajima, S., 28th June, 2005) and (c) a photo at a later date from the same location $\left(37.259828^{\circ} \mathrm{N}, 138.876801^{\circ} \mathrm{E}\right)$ as above (Photo by Konagai, K., 19th September, 2010). 


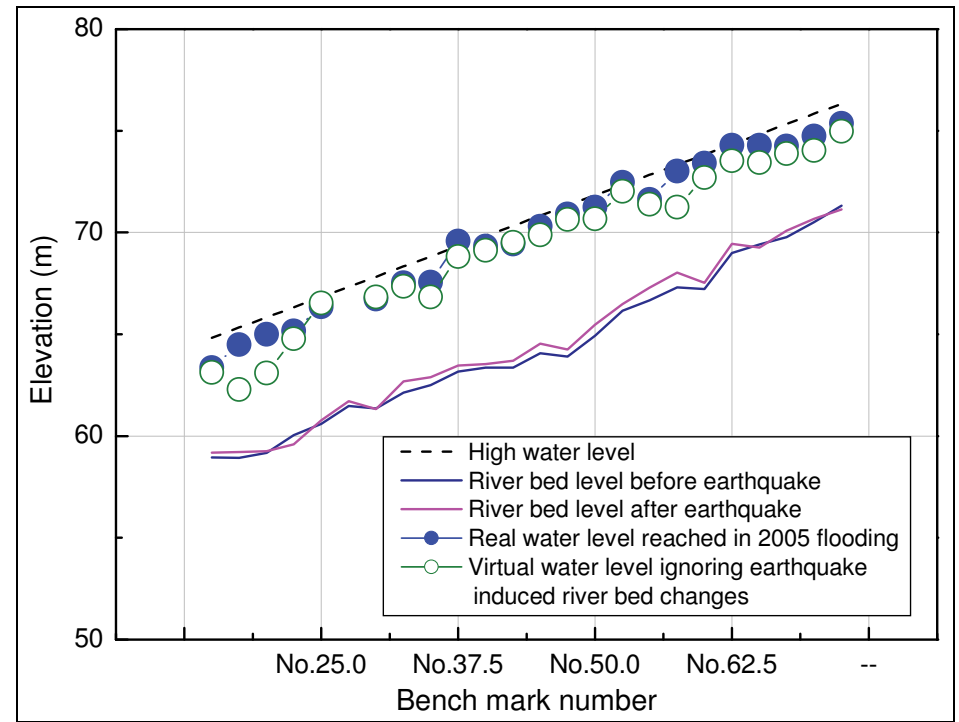

Fig. 14. Water level reached during the flood and the virtual water level estimated from manning's formula.

\subsubsection{Shallow soil displacement}

A strong earthquake usually disturbs the soil/rock mass, especially near the ground surface. Although there is demand of immediate rehabilitation and reconstruction of the damaged facilities, it is very important to know whether the soil mass around that facility is stable enough to start the reconstruction work. Otherwise, we will have to face the same problems repeatedly. The Mid-Niigata Prefecture Earthquake triggered and/or reactivated a large number of landslides and many hamlets have been rendered uninhabitable (Kieffer et al., 2006). The authorities responsible for the reconstruction were especially careful about the reactivation of hidden landslide during the snow melt seasons. Reconstruction/ rehabilitation of Kizawa tunnel (Konagai et al., 2009) is selected as an example case to discuss the shallow soil displacement.

A 300m long ring shaped Kizawa tunnel skims the NW-SE trending branch of Futagoyama Mountain ridge (Figure 16). During the earthquake, the tunnel experienced significant damage. The damage was mainly cracking (Figure 15). The cracks formed two parallel pairs, through the east and west walls, near the north entrance of the tunnel while its crown was shifted sideways by about a half meter (Konagai et al., 2009). Kizawa locality lies on the exposed slip surface of an old landslide whose escarpment is marked by blue broken line in Figure 16 (National Research Institute of Earth Science and Disaster Prevention, NIED, 2008).

Core samples collected from the boreholes near the cracked portion and hydro-geological properties of the soil/rock suggested presence of a thin shear plane of mud stone which was crushed significantly (Konagai et al., 2009). This shear plane, dipping about $10^{\circ}$ south, was found parallel with the intact bed stratum.

Northern 40 to 80 meter length of the tunnel was embedded below this shear plane while the remaining southern part lies in the upper disturbed soil mass. The tunnel was thus obliquely 
bisected by this shear plane. Measurement of the change in alignment of road center line showed that the length of tunnel above the shear plane shifted 0.5 to 1 meter east to southeast wards (Nagaoka Regional Development Bureau, Niigata Prefecture Government, 2008). This suggests that the upper soil mass slipped coherently down this shear plane, gripping southern part of the tunnel which lies in that upper disturbed soil mass.
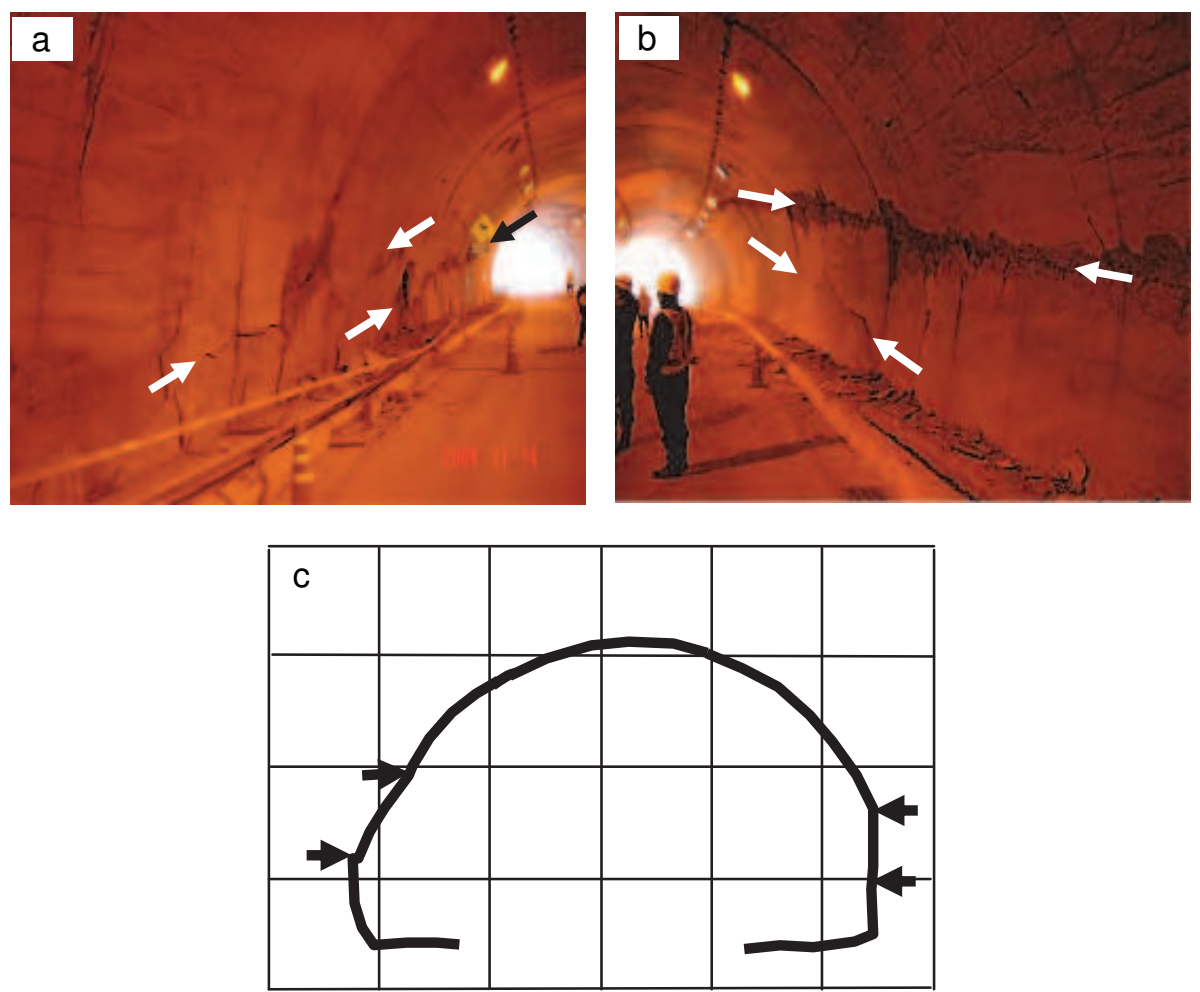

Fig. 15. Diagonal cracks on both walls of Kizawa Tunnel (a) the west wall of the tunnel (b) the east wall of the tunnel c) cross section at $57 \mathrm{~m}$ from the north entrance

In addition to the Kizawa tunnel, two drainage wells (Well A and B in Figure 16) were found dislocated. Well A was dislocated by $0.15 \mathrm{~m}$ at a depth of $34 \mathrm{~m}$ below ground level. The shaft above this dislocation point was inclined indicating $0.5 \mathrm{~m}$ southeast wards movement of the ground. Although the direction of dislocation could not be investigated for such a narrow well, well B was also dislocated at a depth of $20 \mathrm{~m}$ below ground level.

These two dislocated wells and the diagonal cracks that appeared in Kizawa Tunnel make up a large triangle. This triangle infers a large hidden shear plane extending far beyond the south mouth of Kizawa Tunnel with the azimuth of its strike and dip angle being about $100^{\circ}$ and $6^{\circ}$, respectively. This plane is almost parallel with the exposed planar slip surface of an old landslide in Kizawa locality, and its azimuth and dip angle are not much different from those for the cutting plane inferred from the diagonal cracks that appeared in Kizawa Tunnel. However, the problem was to know the extent of this shear plane and to ensure the stability of the upper disturbed soil mass against further slippage during the snow melt season. 


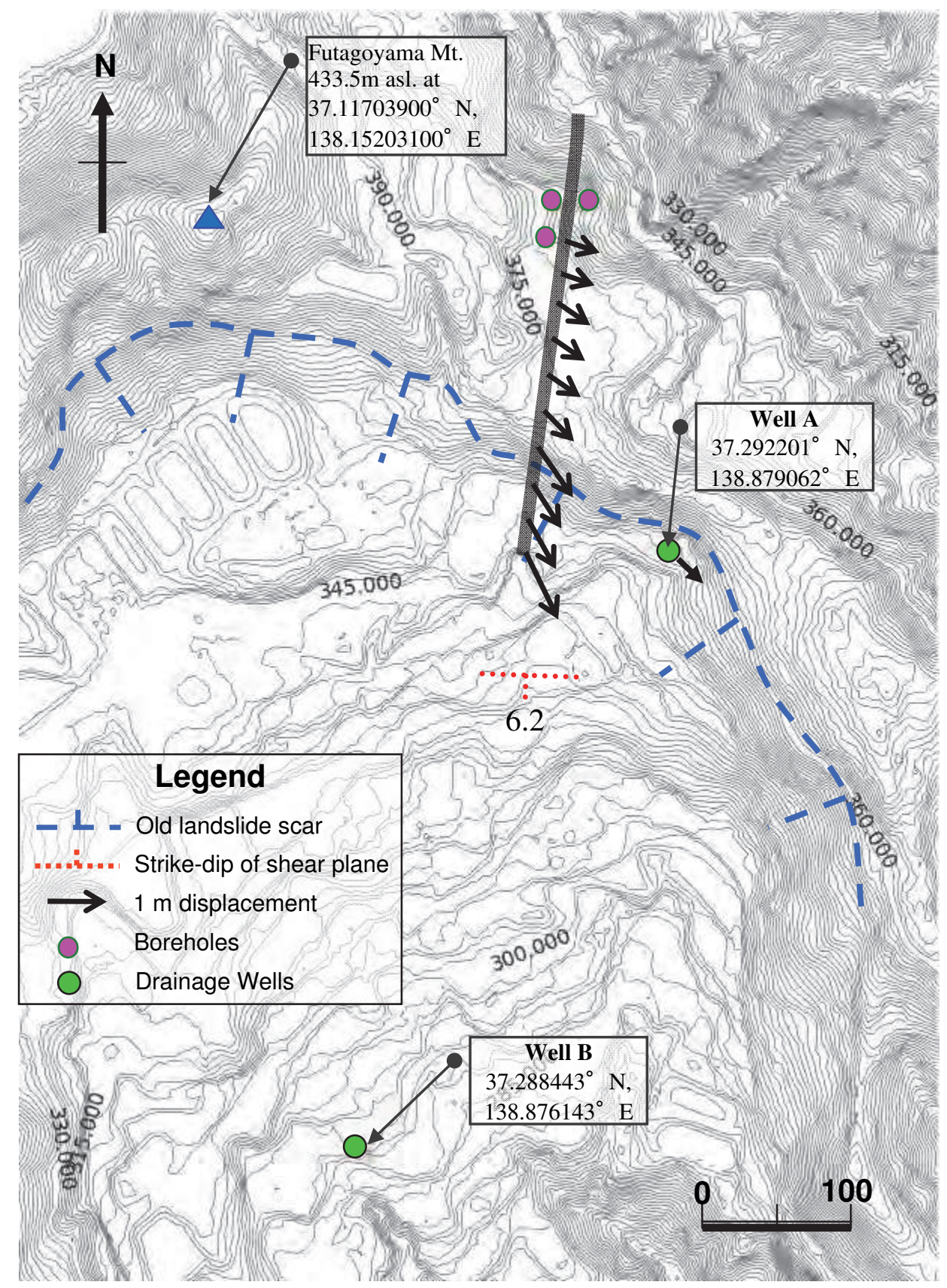

Fig. 16. Topography of the Kizawa hamlet showing inferred shear plane in the interior of soil mass. 


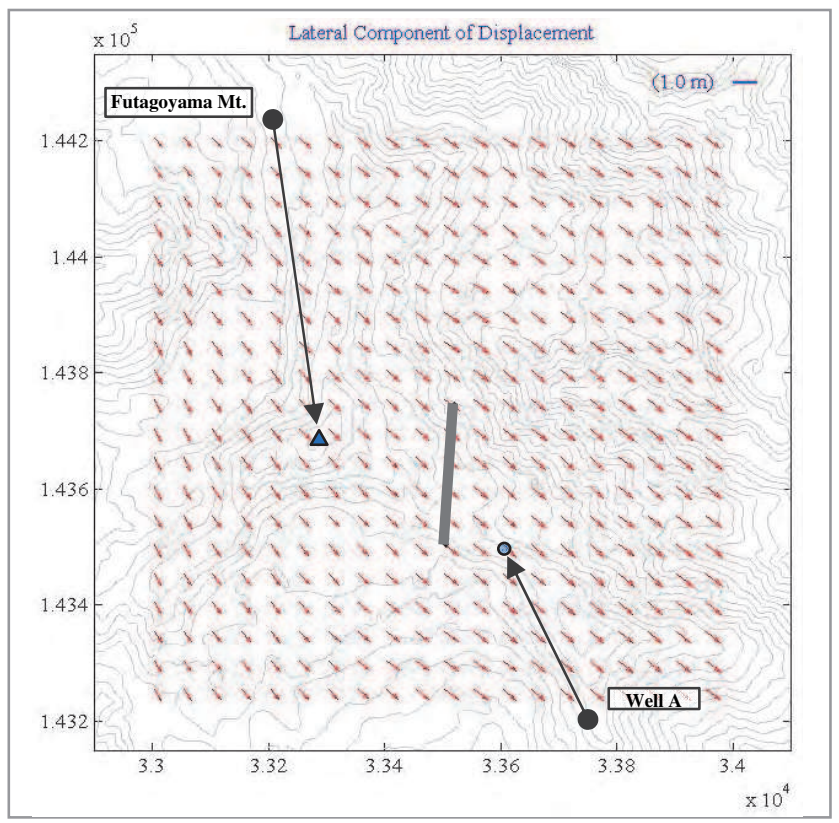

Fig. 17. Lateral component of Surface tectonic displacement of the Kizawa hamlet on Japanese National Grid System, Zone VIII

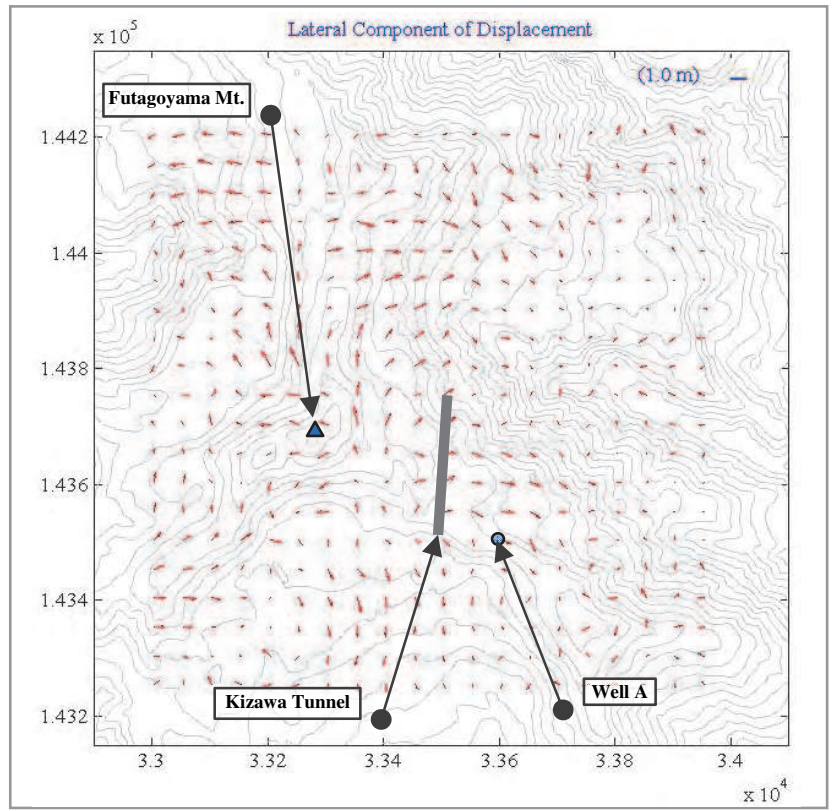

Fig. 18. Lateral component of shallow soil displacement of the Kizawa hamlet on Japanese National Grid System, Zone VIII 
Focusing only to Kizawa hamlet and finding out the Lagrangian components of the estimated tectonic displacements, it is found that the whole area has moved laterally in southeast direction (Figure 17). Scaling down the smoothing window to $200 \mathrm{~m} \times 200 \mathrm{~m}$, an image of shallow soil displacement is obtained. Subtracting the surface tectonic displacements, obtained through the $1400 \mathrm{~m}$ square smoothening window, form those of soil displacements obtained through the $200 \mathrm{~m}$ square smoothening window, gives clearer image of shallow soil displacements only (Figure 18). It suggests that soil masses on all sides of Futagoyama Mountain have moved down the slopes by 0.5 to $1 \mathrm{~m}$. The displacement vectors are well consistent with the direction of dislocation of drainage well and Kizawa tunnel.

\section{Conclusions}

Aftermaths of an earthquake are often more devastating than its immediate effect, especially in the mountainous terrain where most of the earthquakes occur. Large strains built up in soils and rocks along a dislocated fault can also trigger post-earthquake disasters such as landslides and debris flows, which can last long causing serious problems for rehabilitations and land conservations. It is, therefore, important to monitor the landform changes to understand the possibility of any hazard. The Mid-Niigata Prefecture Earthquake provided us a good opportunity to study terrain dynamics. A method is proposed and updated to extract Lagrangian components of soil displacement from a set of DEM's before and after the earthquake.

For establishing well conditioned set of equations and smoothness of the result, landslides and large scale manmade changes were filtered out. While comparing with the landslide map of the target zone, it can be deduced that the filtering criteria traces out landslides and large scale manmade changes successfully. The Lagrangian components of tectonic surface displacement were then determined using $1400 \mathrm{~m}$ square smoothening window. Clusters of large lateral displacement vectors are concordant with the thick clusters of landslides. Vertical components show that the southwestern corner of the target zone is lifted up by 0.5 to $1 \mathrm{~m}$. This is the confluence point of Shinano and Uono Rivers and the benchmark measurements along Uono River show that river bed is elevated by almost the same magnitude. Thus the vertical components of surface tectonic displacements in the target zone also correlate with the field measurements/observations. Flooding of the upper reach of Uono River during heavy rains of 2005 strengthens the evidence of raised river bed.

Shallow soil displacements can be obtained by subtracting the displacement vectors obtained from a $1400 \mathrm{~m}$ square window from that of a $200 \mathrm{~m}$ square window. The shallow soil displacements were obtained for Kizawa locality. In this Kizawa locality, Kizawa tunnel was damaged by two pairs of parallel cracks. Furthermore, two drainage wells were also found dislocated in this locality. This all suggest the presence of a hidden shear plane. The shallow soil displacement vectors obtained for this locality are well consistent with the slip direction of the shear plane.

\section{References}

De Martonne, E. 1927. Regions of interior basin drainage. Geographical Review 17:397-414. Dooge, J.C.I. in (1992): Yen BC, editor. Channel wall resistance: Centennial of Manning's formula. Littleton, Colorado, Water Resources Publications. 
Honda, R., Aoi, S., Sekiguchi, H., Morikawa, N., Kunugi, T., and Fujiwara, H. (2005) Ground motion and rupture process of the 2004 Mid Niigata Prefecture Earthquake obtained from strong motion data of K-net and KiK-net. Earth Planets Space, 57, 527532.

JSCE Active folding Project (2008) Earthquake Damage in Active-Folding Areas: Creation of a comprehensive data archive and suggestions for its application to remedial measures for civil-infrastructure systems (2005-2007) Research and Development Program for Resolving Critical Issues, Special Coordination Funds for Promoting Science and Technology, (Core research organization: JSCE, Leader: K. Konagai).

Kato, H. and Akabane, H. (1986) Geology of Nagano District, with geological sheet map at 1:50,000. Geological Survey of Japan. 120.

Kazuhito Hikima and Kazuki Koketsu. (2005). Rupture processes of the 2004 Chuetsu (midNiigata prefecture) earthquake, Japan: A series of events in a complex fault system. Geophysical Research Letters. VOL. 32, L18303, 5.

Kieffer, D.S., Jibson, R., Rathje, E.M. and Kelson, K. (2006) Landslides triggered by the 2004 Niigata Ken Chuetsu, Japan, Earthquake. Earthquake Spectra. 22, S47-S73.

Kim Haeng Yoong1 and Atsumasa Okada (2005): Surface deformations associated with the October 2004 Mid-Niigata earthquake: Description and discussion. Earth Planets Space, 57, 1093-1102

Konagai, K., Fujita, T., Ikeda, T. and Takatsu, S. (2009) Tectonic deformation buildup in folded mountain terrains in the October 23, 2004, Mid-Niigata earthquake. Soil Dynamics and Earthquake Engineering. 29(2), 261-267.

Konagai, K, Takatsu, S. Kanai, T., Fujita, T., Ikeda, T. and Johansson, J. (2009). Kizawa tunnel cracked on 23 October 2004 Mid-Niigata earthquake: An example of earthquakeinduced damage to tunnels in active-folding zones. Soil Dynamics and Earthquake Engineering. 29(2), 394-403.

Nagaoka Regional Development Bureau, Niigata Prefectural Government, and Honma Corporation (2007) Construction Report of Kizawa Tunnel of the OjiyaKawaguchi-Yamato Line, D-16(4903-00-00-03) [in Japanese].

National Research Institute for Earth Science and Disaster Prevention (NIED) and Japan Science and Technology Agency (2008) Landslide Map Database.

http://lsweb1.ess.bosai.go.jp/jisuberi/jisuberi_mini_Eng/jisuberi_top. htmlS.

National Institute of Earth Science and Disaster Prevention. (2004) Mid Niigata Earthquake. http://www.hrr.mlit.go.jp/saigai/H161023/1023_top.htmlS

Oyagi, N., Uchiyama, S. and Inokuchi, T. (2008) Map of Landslides Caused by the 2004 Niigata-ken Chuetsu (Mid Niigata) Earthquake (MJMA=6.8). Technical Note of the National Research Institute for Earth Science and Disaster Prevention, 317.

Ozawa, T., Nishimura, S., Wada, Y. and Okura, H. (2005) Coseismic deformation of the Mid Niigata prefecture earthquake in 2004 detected by RADARSAT/InSAR. Earthquake Planets Space. 57, 423-428.

Report of Zenkoji Earthquake, Central Disaster Prevention Council (2008), http://www.bousai.go.jp/jishin/chubou/kyoukun/rep/1847-zenkoJISHIN/

United States Geological Survey (2005) "What is InSAR?" Earthquake Hazard Program. http://quake.usgs.gov/research/deformation/modeling/InSAR/S, 2005. 
Yanagisawa, Y., Kobayashi, I., Takeuchi, K., Takeishi, M., Chihara, K. and Kato, H. (1986) Geology of the Ojiya District. Quadrangle Series Scale 1:50,000, Niigata (7), 50. Geological Survey of Japan. 


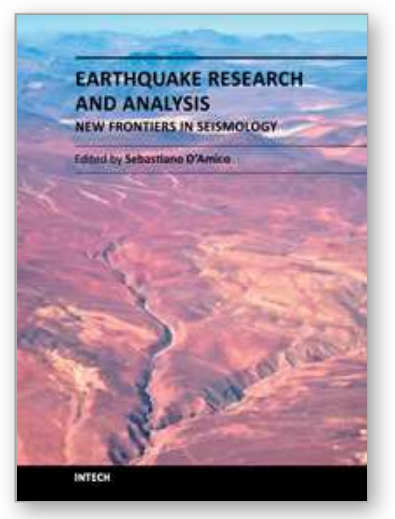

\author{
Earthquake Research and Analysis - New Frontiers in Seismology \\ Edited by Dr Sebastiano D'Amico
}

ISBN 978-953-307-840-3

Hard cover, 380 pages

Publisher InTech

Published online 27, January, 2012

Published in print edition January, 2012

The study of earthquakes combines science, technology and expertise in infrastructure and engineering in an effort to minimize human and material losses when their occurrence is inevitable. This book is devoted to various aspects of earthquake research and analysis, from theoretical advances to practical applications. Different sections are dedicated to ground motion studies and seismic site characterization, with regard to mitigation of the risk from earthquake and ensuring the safety of the buildings under earthquake loading. The ultimate goal of the book is to encourage discussions and future research to improve hazard assessments, dissemination of earthquake engineering data and, ultimately, the seismic provisions of building codes.

\title{
How to reference
}

In order to correctly reference this scholarly work, feel free to copy and paste the following:

Kazuo Konagai, Zaheer Abbas Kazmi and Yu Zhao (2012). Extracting Earthquake Induced Coherent Soil Mass Movements, Earthquake Research and Analysis - New Frontiers in Seismology, Dr Sebastiano D'Amico (Ed.), ISBN: 978-953-307-840-3, InTech, Available from: http://www.intechopen.com/books/earthquake-researchand-analysis-new-frontiers-in-seismology/extracting-earthquake-induced-coherent-soil-mass-movements

\section{INTECH}

open science | open minds

\section{InTech Europe}

University Campus STeP Ri Slavka Krautzeka 83/A 51000 Rijeka, Croatia Phone: +385 (51) 770447

Fax: +385 (51) 686166 www.intechopen.com

\section{InTech China}

Unit 405, Office Block, Hotel Equatorial Shanghai No.65, Yan An Road (West), Shanghai, 200040, China 中国上海市延安西路65号上海国际贵都大饭店办公楼 405 单元 Phone: +86-21-62489820

Fax: $+86-21-62489821$ 
(C) 2012 The Author(s). Licensee IntechOpen. This is an open access article distributed under the terms of the Creative Commons Attribution 3.0 License, which permits unrestricted use, distribution, and reproduction in any medium, provided the original work is properly cited. 